\title{
1 Patterns in the journalistic selection of neuroscientific research results
}

2 Sarah Kohler $^{1^{*}}$, Nikolai Promies ${ }^{1}$, Markus Lehmkuhl ${ }^{1}$

$3{ }^{1}$ Department of Science Communication, Karlsruhe Institute of Technology, Karlsruhe,

4 Germany

$5 \quad *$ Correspondence: sarah.kohler@kit.edu

6 Keywords: science communication; neuroscience; science journalism; media attention; 7 news selection

\section{Abstract}

9 This study compares the journalistic selection of scientific results from the field of neuroscience with other scientific disciplines. Based on an input-output analysis using data from the citation database Scopus and the alternative bibliometrics provider Altmetric, we investigated which scientific studies from which scientific journals have been selected by global journalism.

13 Previous research suggests that the selection of sources and results in science journalism 14 follows a certain heavy-tailed distribution, a power law. This structure of journalistic coverage 15 is a result of conditions on the micro-level of actions and decisions of individual journalists. 16 Among these conditions are restrictions that derive from the process and constitution of scientific publishing and research results. We argue that the parameter of such power law distributions can potentially be used to describe selectivity in journalism on a high aggregation level. Differences in the value of the parameter point to differences in the conditions present on the micro-level. To test this assumption, we chose a field of research that has attracted a considerable degree of public attention over the last few years: neuroscience. We expected to find differences in the exponent of power law distributions between neuroscience and other scientific disciplines. Our results show that the frequency distribution of journalistic references to single studies and journals in the coverage of neuroscientific research can be described by a power law. The selection of scientific journals is more homogenous in neuroscience in the sense that there is a less pronounced dominance of just a few journals. It is proposed to interpret this as an effect of the greater popularity of neuroscience. 


\section{Introduction}

Journalistic work and especially journalistic news selection has always been characterized by a number of restrictions. Most journalists have to make a number of complex decisions (which event to report on, which sources to use for coverage, which focus to set...) in a short amount of time, often without having all or sufficient knowledge to base these decisions on and in a situation of competition with other media. This also applies to science journalism. Here, restrictions derive, among others, from the process and constitution of scientific publishing and research results. One of the biggest challenges for science journalists is the unmanageable amount of new research papers they have to deal with. Millions of new scientific results, which journalists could report on, are published each year. It is clearly impossible to read them all in order to select the best fitting paper for media coverage. To deal with this, however, science journalists do not randomly select research papers for their coverage. Instead, journalism has to adjust criteria for this selection, e.g. focusing on just a few scientific journals, as some studies have already shown (e.g., Blöbaum et al., 2004; Hansen, 1994; Rosen et al., 2016).

In a previous study, we have shown that the specific conditions and selection criteria in the journalistic coverage of new scientific results lead to an uneven frequency distribution of selected studies and journals (Lehmkuhl \& Promies, 2020). In line with the argumentation of Esser's model of sociological explanation (1999), we assume that this social structure of congruent choice on the macro-level, i.e. the journalists' selection of scientific journals and single research results, is a result of the behavior of individual journalists on a micro-level. We assume that the parameters of such distributions can be applied to compare the degree of congruent selection of studies and journals in science journalism. To test this assumption, we will focus on the coverage of one specific area of science and compare it with all other scientific fields. For our study, we chose neuroscience, a discipline that has received extraordinary public attention over the last years, possibly leading to changes in the interactions between journalists and scientists from this field.

Following Pickersgill (2013, p. 324), we will use a broad definition of neuroscience as "the scientific study of the nervous system, including the brain.” Since the beginning of the 1990s, this field of research has seen an enormous growth and expansion to a number of topics such as addiction, emotions or learning. Among these topics are many with large societal implications and that have traditionally been the focus of the humanities or social sciences (AbiRached, 2008; O'Connor \& Joffe, 2013a). This expansion even exceeds academic research and extends into many fields of society, leading scholars to speak of a "neuro-age” (Abi-Rached, 
2008, p. 1162), “neuroculture” (Frazzetto \& Anker, 2009) or other "neurologisms” like neuroethics or neuromarketing (Illes et al., 2010, p. 61). Parallel to the growth of the field, there has been a rising public and media interest for neuroscience. Content analyses have shown that the amount of coverage on neuroscientific research has grown in a number of countries (e.g. Jong et al., 2016; O'Connor et al., 2012; Racine et al., 2010) and ideas and concepts from neuroscience influence public and private discussions (O'Connor \& Joffe, 2013a; Rodriguez, 2006).

One reason for the large public interest in neuroscience is that it addresses philosophical and social questions that have been discussed for decades or centuries, for example about the existence of a free will (Racine et al., 2017), the "right" way to raise children (O'Connor \& Joffe, 2013b) or gender differences (O'Connor \& Joffe, 2014). Neuroscientific results promise to give evidence-based answers to many of these questions. An important role for the communication of these results plays the ability to show "proof" of statements about human behavior with imaging technologies like fMRI (Beck, 2010; O'Connell et al., 2011; Racine et al., 2006). As consequence of the rising public interest in neuroscientific research, many authors see a growing pressure on neuroscientists to publish the results and implications of their research. Surveys have shown that "interactions with the media have become part of the routine work in (neuro)science independently of whether researchers personally welcome such activity or not” (Allgaier et al., 2013b, p. 418). Most of the surveyed neuroscientists expect positive consequences of public visibility and assume that journalistic coverage has a large influence on the public opinion and political decision-making on scientific topics (Allgaier et al., 2013a, 2013b; Koh et al., 2016).

In summary, neuroscience differs from many other disciplines in that it has received considerable public and media attention. This attention also has repercussions on the work of neuroscientists. We expect to find traces of this exceptional situation in our analysis of the journalistic coverage of neuroscientific research. Based on an input-output-analysis, our study investigates which scientific studies and scientific journals are preferably selected by global journalism. Further, we examine whether there are differences in the selection of neuroscientific research papers compared to papers of other research areas.

\section{Social structure as result of journalists' decisions}

The journalistic selection of research results is a highly complex process in which individual journalists have to make a multitude of decisions. During this process, they encounter a number 
of restrictions they have to reduce to maintain functionality (Donsbach, 2004; Schimank, 2005). We assume that the decisions of individual actors lead to a social structure that becomes visible if the individual selections are aggregated to collective behavior (Reinemann \& Huismann, 2007). The theoretical approach of this study thus is based on the assumptions of sociologists Hartmut Esser (1999) and James Coleman (1991). The model of sociological explanation ['Modell der soziologischen Erklärung'] defines social structures as the results of actions and decisions of individual actors. Esser describes three bridging hypotheses between the macrolevel of social structures and the micro-level of individual actions as 'logics' for the development of social structures: First, the logic of situation, second, the logic of selection, and third, the logic of aggregation. The last step reveals a measurable effect, which is the aggregation of the former individuals' decisions and actions. In the following, each of these three logics will be transferred to science journalists and their decision-making process in the selection of research results.

\subsection{The logic of situation}

Esser (1999, p. 94) describes the logic of situation as the general conditions and socio-cultural premises which individuals encounter in their actions. These include restrictions and limitations, as well as the environment in which the actors operate. The journalistic selection of new scientific results for media coverage is affected by changes and developments in the journalistic system as well as in the scientific system.

The work of journalists has undergone a number of far-reaching changes over the last decades which have been comprehensively described in research literature (e.g., Kiefer, 2005). Changes in external conditions such as the expansion of media, loss in reach and advertisers, and flood of information have influenced the internal conditions for media organizations (economization, competitive pressure, audience orientation) and internal conditions for journalists (time pressure, role expectations) (Reinemann \& Huismann, 2007, p. 480). Especially relevant for the complexity of journalistic decision-making is the time pressure under which journalists work. These circumstances affect global journalism equally. Journalists from 16 countries all over the world emphasize the impact of outer influences on their work which can be described as time scarcity, standards and procedures of news production, and lack of resources (Hanitzsch, 2009). Science journalism is affected by the same developments. Especially lack of time and the resulting pressure turn out to be key factors which influence the daily work of science journalists (Amend \& Secko, 2012). 
Additionally, the technical advances in scientific publishing have a strong impact on science journalism (Granado, 2011). Over the last decades, processes of publishing have accelerated immensely. Likewise, the number of published research articles has grown at an annual rate of about three percent. Open access and open science publishing has even increased by 30 percent per year since 2000 (Bornmann \& Mutz, 2015; Laakso et al., 2011). To cite an example, the scientific database Scopus which enlists scientific articles and reviews is growing by 5,000 new results each day (Elsevier, 2017). The enormous growth and specialization of the literature corpus makes it nearly impossible for outsiders like journalists to assess the relevance of single research papers (Scheufele, 2013). The relevance of a single result for science or society can only be assessed in the context of other research results. Journalism cannot accomplish this because it massively exceeds its capacity in terms of time, resources and knowledge. Additionally, trust in the integrity of science knowledge production has been damaged over the last years (Cortiñas-Rovira et al., 2015). One factor is the emergence of predatory journals which have no peer review or quality control (Beall, 2013; Demir, 2018; Manca et al., 2018). Rising doubts about the reliability of scientific results could lead to an even stronger orientation towards well-established journals with a high reputation.

Another important aspect of the situation of journalistic news selection is the influence of third parties (such as interactions with other journalists, with sources, and with recipients). Studies indicate that science journalists read and observe other influential media titles such as New York Times, BBC, Nature, and Science (Granado, 2011; Lehmkuhl \& Peters, 2016), but are rather not affected by their colleagues' choices. Instead, science journalism has to deal with increasingly professional science PR departments (Lehmkuhl, 2019; Schäfer, 2011). Scientists and their institutions try to demonstrate the social relevance of their own actions to political elites with references in prestigious media (Marcinkowski et al., 2014; Peters et al., 2013). Recipients are probably another influential group for science journalism. As the loss of reach has increased in the past years, bonding with the audience became crucial for media organizations. Attempts to strengthen this bonding include an increasing participation of recipients (Domingo et al., 2008) and the alignment of news selection with the preferences and expectations of the audience (Dogruel \& Beck, 2017).

\subsection{The logic of selection}

The logic of selection (Esser, 1999, 94ff.) describes how individuals select from several alternative actions. Based on the described conditions, science journalists have to choose from an unmanageable amount of new research papers whose public relevance can only be assessed 
158

159

160

161

162

163

164

165

166

167

168

169

170

171

172

173

174

175

176

177

178

179

180

181

182

183

184

185

186

187

188

189

190

in very exceptional cases. Given the sheer number of new research articles, it is impossible for journalists to read them all and to judge whether they might fit for media coverage. Therefore, other indicators than the knowledge of the content of all papers have to be used for the selection of research papers in the first place. Selection criteria in journalism have been comprehensively examined and described. Popular approaches such as news values try to explain the selection of news for media coverage based on characteristics of the events that are reported on (Eilders, 2006; O'Neill \& Harcup, 2008). There have also been attempts to transfer the concept of news values to science journalism (e.g. Badenschier \& Wormer, 2012; Mellor, 2015). We won't describe the potential influence of news values here because it is implausible that they are relevant at the stage of news selection we are interested in. Given the enormous number of new results journalists could possibly report on, it is impossible that journalists estimate the possible news value of each result and then choose the result with the highest news value. And it is likely that most days, there would be a number of results with a similar news value. Therefore, news values can only play a role in the news selection when there has already been some sort of preselection. One such mechanism of preselection could be the preference for results that are accompanied by a press release (Bartlett, 2002; Semir, 1998; Stryker, 2002).

In the following and later on in the analysis we will focus on another very important criterion for the selection of the scientific results. Sources are a very plausible criterion for journalistic selection (Blöbaum et al., 2004; Moriarty et al., 2010). The sheer amount of scientific research and the conditions of the journalistic and scientific system have led to a strong orientation towards just a few well-established journals (Franzen, 2011; Hansen, 1994; Rosen et al., 2016). Semir (1998) analyzed the science coverage of seven large international media titles and found that one third of all covered scientific research was from just four journals. Pahl (1997) found similar shares for eight German media titles: 75 percent of more than 400 references to scientific journals refer to only ten journals. Even more, half of these refer only to the three journals Nature, Science, and New England Journal of Medicine (NEJM). Studies by Suleski and Ibaraki (2010) and Kiernan (2016) also showed the dominance of just a few journals in the media coverage of scientific results. Lehmkuhl and Promies (2020) have summarized all studies which analyzed science journalists' preferred sources. They discovered that journalistic coverage of scientific results is primarily based on the journals Nature, Science, New England Journal of Medicine (NEJM), The Lancet, and the Journal of the American Medical Association. The order differs depending on the sample of analyzed media titles and topics. Most of these studies focus on medicine as topic or medical studies. The comparison to other research areas is lacking. 


\subsection{The logic of aggregation}

192 Esser (1999, pp. 96-100) describes the logic of aggregation as transformations in which the

193

194

195

196

197

198

199

200

201

202

203

204

205

206

207

208

209

210

211

212

213

214

215

216

217

218

219

220

221

222

223

actions and decisions from the previous steps lead to specific and measurable effects. Even more, the measurability can be specified as transformation rule which is always applicable in a specific aggregation (Dimbath, 2012, p. 110; Schneider, 2005, p. 170). Referring to science journalism, this indicates that such a rule must represent a consistent and mathematical describable formula of the structure of the journalistic selection. This structure is the aggregation and result of the actions and decisions of journalists. As explicated above, the situation within the journalistic and scientific system as well as the selection criteria of science journalists probably lead to the focus on just a few well established journals while other sources are rarely selected. Such a distribution of selection and choice always occurs if there is an almost infinite amount of options from which people have to choose. Similar skewed distributions have been found for a number of social and natural phenomena, amongst them the use of websites or the distribution of topics in online news (Anderson, 2009; Smyrnaios et al., 2010). They follows specific mathematical function, a so-called power law. Power laws are long tailed distributions which match a straight line on logarithmic scales and follow a function of the form $C * x^{-\alpha}$ (Clauset et al., 2009; Newman, 2005).

Based on the review of several previous studies and their own data from an input-output analysis, Lehmkuhl and Promies (2020) found that power law distributions (or a variation, a so-called truncated power law) are present in the distribution of journalistic references to scientific journals and single results. The share of studies that are selected by a certain number of media titles decreases by a factor of about $1 / \mathrm{x}^{4}$ with every additional media title. The share of journals with a certain number of studies that were selected by journalists decreases by a factor of about $1 / \mathrm{x}^{2}$ with every additional selected study. While there are many journals with one selected study over a period of two years, there are very few with thirty or more. We propose that this power law distribution can be regarded as a transformation rule which allows us to aggregate the selection decisions of many journalists to an observable structure, the frequency distribution of the selection of journals or single results. The most important aspect of this transformation rule is the exponent $\alpha$ of the power law distribution. We assume that the value of this exponent changes based on the specific situation or selection mechanisms that are present in a specific area of journalism. In other words: the exponent of the power law distribution is an indicator for differences between different journalistic fields, media markets or time periods. 
224 To test this assumption, this study builds on the results of (Lehmkuhl \& Promies, 2020) and 225 tests the performance of this indicator for the comparison of different journalistic fields. We aim to examine the structures of journalistic selectivity for neuroscientific research results compared to scientific research in general. Since neuroscience has been a topic of rising public interest over the last decades and some works point to possible effects of medialization on neuroscience, we assume that the conditions in the journalistic coverage of neuroscientific research should be different from other fields. Based on the previous results, we want to test two assumptions and investigate one research question. We assume that the frequency distribution of journalistic references to single scientific results in the coverage of neuroscientific research can be described by a power law distribution. In addition, we assume that the frequency distribution of journalistic references to scientific journals in the coverage of neuroscientific research can be described by a power law distribution as well. scientific journals and single results between neuroscience and other scientific disciplines?

\section{Method}

\subsection{Sources and datasets}

241 To examine the frequency distributions of the selection of journals as sources and the selection 242 of single results as triggers of media coverage, we conducted an input-output analysis. We 243 combined datasets from two sources to investigate which scientific studies from which 244 scientific journals have been selected by global journalism to a relevant degree: First, the 245 abstract and citation database Scopus, second, the alternative bibliometrics provider Altmetric.

246 Scopus, which is run by Elsevier, records more than 30,000 peer reviewed journals and about three million new articles annually (Johnson et al., 2018). Each day, over 5,000 new studies are added (Elsevier, 2017). We exported all research papers of the type 'new study result' with publication dates between August 2015 and July 2018 from Scopus. These approximately six million articles function as the input data set for the analysis. We exported metadata such as the title, source, authors and digital object identifier (DOI) for each study. The DOI was then used to retrieve data from Altmetric representing the amount of media attention a study received.

253 Altmetric provides a variety of different metrics meant to show the societal impact of research 254 results (Adie \& Roe, 2013, p. 11). For our analysis, we used the mainstream media (MSM) score. The MSM score indicates in how many online media portals a study was mentioned, e.g. 
a score of 15 means that 15 different online portals mentioned the study. It is based on the tracking of a list of over 2,000 online media titles which was compiled by Altmetric. The list includes a number of websites that do not represent real media attention. For example, it contains a number of aggregator sites. Aggregator sites collect information, usually provide a link to the original source and function as mere disseminators e.g. of press releases. Therefore, low MSM scores are no reliable indicators of journalistic attention. Hence, it is necessary to validate from what level the MSM score can actually be applied as indicator for journalistic selectivity before the scores from Altmetric can be used as output dataset.

\subsection{Validation of the MSM score}

We conducted two steps for the validation of the MSM score regarding type I error (false positive; high MSM score and no press coverage) and type II error (false negative; no/low MSM score and high amount of press coverage). The first validation was meant to reveal which values of the MSM score definitely point to press coverage, the latter examined if there are studies which have no MSM score (i.e. MSM score =0) but where covered by media.

For the first validation, all research papers which were published in the journals Science (753 articles) and Nature (848 articles) from January to October 2017 were extracted from Scopus ( $\mathrm{N}=1601$ research papers in total). These articles were assigned to eleven categories depending on their MSM score (scores of 1-9; 10-19; 20-29; ...; $\geq 100$ ). Then, five randomly selected articles were chosen for each category $(\mathrm{N}=55)$. For each study, a manual search was conducted in the full text press database of LexisNexis (LexisNexis, 2020) for three large national media markets (United Kingdom, the United States, and Germany). The category of scores $\geq 100$ was the only group for which we found press coverage for each study. Additionally, for three studies in this group we were able to identify a considerable amount of articles (19 or more). Therefore, and in order to reduce the type I error, only studies with an MSM score $\geq 100$ were used in this analysis. We call these studies ‘social impact papers’ (SIP, see Lehmkuhl \& Promies, 2020).

The second validation aimed to reveal if the MSM score might miss relevant studies that received media attention. All research papers from the Scopus subject area medicine, which were published in the randomly chosen months October and December 2016, were extracted from Scopus. Within this sample, Altmetric did not have an MSM score for 934 research papers. Of these studies, 60 papers were randomly selected and it was manually checked whether there was any media coverage on these studies in the LexisNexis press database. This was not the case. Therefore, we assume that if a research paper has no MSM score, it has most likely received no media coverage. 


\subsection{Analysis}

290 Based on the validations, our final dataset consisted of all studies published between August 2912015 and July 2018 with an MSM score of at least 100. To be able to compare different research 292 fields, we categorized each study thematically based on its title, abstract and the journal it was 293 published in. For this study, especially one category is relevant, neurology and neuroscience. 294 In our analysis, we differentiate between social impact papers in general (all research areas 295 296 except neuroscience) and neuroscientific social impact papers (NSIP). To test if power law distributions are plausible representations of our data and to describe the parameters of these distributions, we constructed power law fits based on the methods described by Clauset et al. (2009) ${ }^{1}$. We used the implementation of these methods in the R (R Core Team, 2019) package poweRlaw (Gillespie, 2015). As an additional measure of the inequality present in the selection of scientific journals as sources of media coverage, we calculated the Gini coefficient and

302 Lorenz curve for the distribution of SIP and NSIP on journals.

\section{Results}

303

304

305

306

307

308

309

310

311

312

313

314

315

316

317

\subsection{Description of the distributions}

Of the about six million studies available in Scopus for the study period between August 2015 and July 2018, only 1,019 had an MSM-score of at least 100. This means that only about 0.01 percent of all results (about 1 in 10,000 studies) received considerable media attention. Of the different research branches, medicine represents the largest share of SIP (37.10\%, $\mathrm{n}=378$ ), followed by neuroscience (14.82 \%, n=151), and biology (8.93\%, n=91). These three disciplines alone already amount to 60 percent of all social impact papers (supplement, table S1). With regard to the MSM score, there are no huge differences between the group of NSIP $(\mathrm{M}=145.27, \mathrm{SD}=46.59$; $\max =336$; median=128) and SIP $(\mathrm{M}=144.47, \mathrm{SD}=47.30 ; \max =414$, median=128.5). The large difference between mean and median points to skewed, heavy-tailed distributions in both cases. There are 247 studies with a score between 100 and 110, but only 42 with a score of at least 250.

The uneven distribution is also visible in the number of SIP per journal (table 1). 225 journals have published 1,019 SIP. Yet, less than a dozen journals represent 45 percent of all SIP (table 1) while there are 122 journals with only one SIP. The journals with the highest amount are

\footnotetext{
${ }^{1}$ For technical details, see supplements.
} 
318 Nature (8.83 \%, n=90), Science (7.56 \%, n=77) and the New England Journal of Medicine (5.99

$319 \%, \mathrm{n}=61$ ). The list is dominated by multidisciplinary and medical journals.

\section{Table 1: Journal and number of all SIP}

\begin{tabular}{lll}
\hline Journal & Number of SIP & \% \\
\hline Nature & 90 & 8.83 \\
Science & 77 & 7.56 \\
New England Journal of Medicine & 61 & 5.99 \\
Proceedings of the National Academy of Sciences of the USA & 49 & 4.81 \\
The Lancet & 45 & 4.42 \\
Jama - Journal of the American Medical Association & 35 & 3.43 \\
Pediatrics & 28 & 2.75 \\
Jama Internal Medicine & 21 & 2.06 \\
Scientific Reports & 21 & 2.06 \\
Nature Communications & 19 & 1.86 \\
Plos One & 18 & 1.77 \\
\hline N = 1019 SIP & &
\end{tabular}

$\mathrm{N}=1019$ SIP

322 If we look at the journals with neuroscientific social impact papers, the list of the "top journals" 323 does not differ a lot from the aforementioned list of journals (table 2). 69 journals have 324 published 151 neuroscientific SIP. Again, Nature (8.61\%, n=13), the New England Journal of 325 Medicine (6.62\%, $\mathrm{n}=10)$ and Science $(5.96 \%, \mathrm{n}=9)$ have the most SIP. The Lancet, Pediatrics, 326 JAMA, and the Proceedings of the National Academy of Sciences of the USA appear on top of 327 both lists, too. Again, these journals own almost 50 percent of all social impact papers in 328 neuroscience while there are 44 journals with only one SIP.

329 Table 2: Journal and number of NSIP

\begin{tabular}{lll}
\hline Journal & Number of NSIP & \% \\
\hline Nature & 13 & 8.61 \\
New England Journal of Medicine & 10 & 6.62 \\
Science & 9 & 5.96 \\
The Lancet & 9 & 5.96 \\
Pediatrics & 7 & 4.64 \\
Current Biology & 5 & 3.31 \\
JAMA - Journal of the American Medical Association & 5 & 3.31 \\
Neurology & 5 & 3.31 \\
Cell & 4 & 2.65
\end{tabular}




\subsection{Power law fits and Gini coefficients}

In the description, we have already mentioned indicators of skewed, heavy-tailed distributions.

In the next step, we will test if a power law is a plausible representation for our data and describe the parameters of the distributions. We start with the distribution of (N)SIP on scores. We estimated power law fits for the frequency distribution of studies with a certain MSM score for neuroscientific studies and studies from all other research fields. The first resulted in an exponent of $\alpha_{\mathrm{NSIP}}=3.97\left(\mathrm{SE}=0.39^{2} ; \mathrm{x}_{\min }=100\right.$; goodness-of-fit test $\left.\mathrm{p}=0.73^{3}\right)$. The other frequency distribution has an exponent of $\alpha_{\mathrm{SIP}}=4.03\left(\mathrm{SE}=0.76 ; \mathrm{x}_{\min }=100\right.$; goodness-of-fit test $\mathrm{p}=0.35$ ). Figure 1 shows the complementary cumulative distribution function (CCDF) on a log-log scale, which is a visualization of the distribution. The left side is the distribution for NSIP, the right side for SIP. The x-axis represents the MSM score. The y-axis shows the share of (N)SIP with at least this score. All studies in our dataset have an MSM score of 100 or higher,

343 leading to a share of 1 for $\mathrm{x}=100$. Only about 10 percent of all SIP have a score of 200 or

344 higher, thus $\mathrm{y}$ is approximately 0.1 for $\mathrm{x}=200$ in the right panel. A first indicator for a power

345 law distribution would be a straight line in the CCDF. The data points follow the lines of the power law fits closely but show a steep drop-off at the end. Anyhow, the goodness of fit test both indicate that a power law distribution is a plausible fit for the data in both cases, in line with our first assumption. The exponents of both distributions are very similar.

\footnotetext{
${ }^{2}$ We used bootstrapping with 10,000 simulations to measure the uncertainty of the estimators and exponent.

${ }^{3}$ The result of the goodness-of-fit test is a p-value. If $\mathrm{p}$ is not significant, we do not reject the power law hypothesis for the distribution, i.e. the distribution fit to be a power law distribution.
} 
a) Neuroscientific social impact papers (NSIP, $\mathrm{n}=151$ )

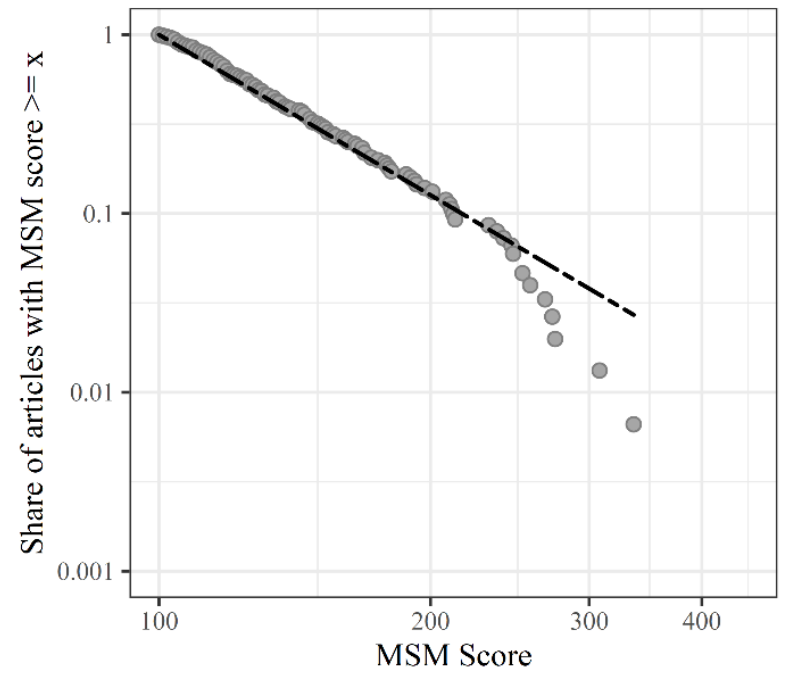

b) Social impact papers from other disciplines (SIP, $\mathrm{n}=868$ )

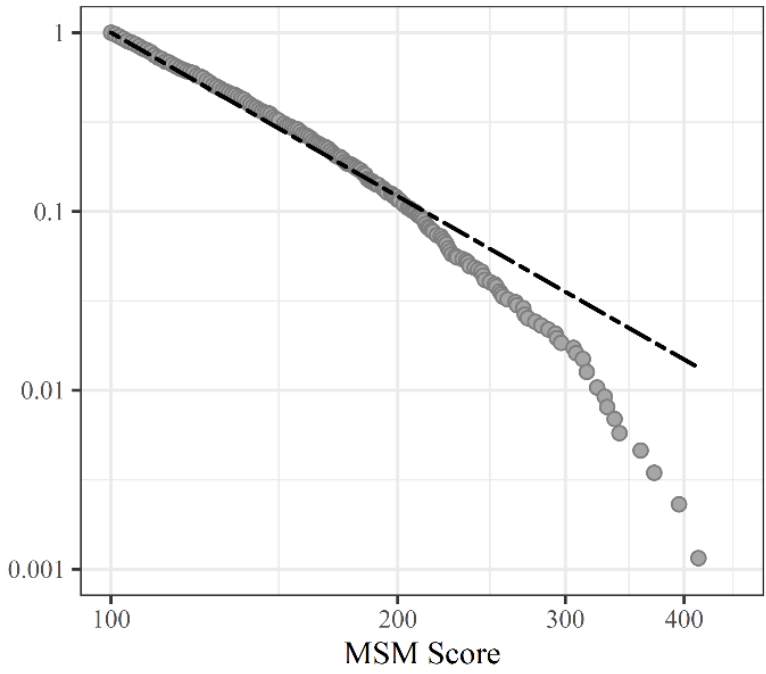

350 We also estimated a power law fit for the journal count (i.e. number of SIP per journal) for

351 NSIP and SIP. The first resulted in an exponent of $\alpha_{\mathrm{NSIP}}=2.15\left(\mathrm{SE}=0.39 ; \mathrm{x}_{\min }=1\right.$;

352 goodness-of-fit test $p=0.76)$. Thus, the probability for a journal to have one more NSIP

353 decreases regularly with $\mathrm{x}^{-2.15}$. In contrast, the distribution for all other research fields has an exponent of $\alpha \mathrm{SIP}=1.92\left(\mathrm{SE}=0.13 ; \mathrm{x}_{\min }=1\right.$; goodness-of-fit test $\left.p=0.11\right)$. Figure 2 again shows the complementary cumulative distribution function (CCDF) of both distributions on a log-log scale. The x-axis represents the number of (neuroscientific) SIP per journal. The y-

357 axis shows the ratio of journals (of the entire sample) which have at least $\mathrm{x}$ (neuroscientific) 358 SIP. In the dataset every journal has at least one SIP, therefore the ratio 1 (y) means 100 359 percent of the entire sample has at least one SIP. Less than half of the journals with NSIP 360 have at least two NSIP. The last dot represents the journal Nature which has 13 SIP $361 \quad(y=0.0144 ; 1.44 \%)$. The right CCDF seems to have a similar structure with a clear decrease. 362 Again, only half of all journals have at least two SIP. The data points again follow a straight 363 line closely in both cases but drop off slightly at the final data points. Yet, the goodness-of-fit364 test shows that a power law is at least plausible for both distributions, in line with our second 365 assumption. 
a) Distribution of neuroscientific social impact papers (NSIP, $n=151$ ) on journals $(\mathrm{n}=69)$

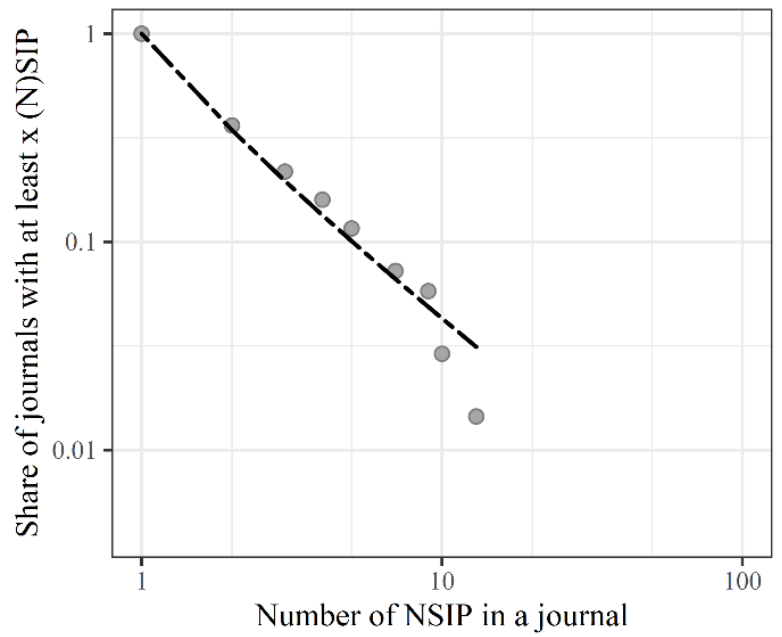

b) Distribution of social impact papers from other disciplines (SIP, $\mathrm{n}=868$ ) on journals $(\mathrm{n}=225)$

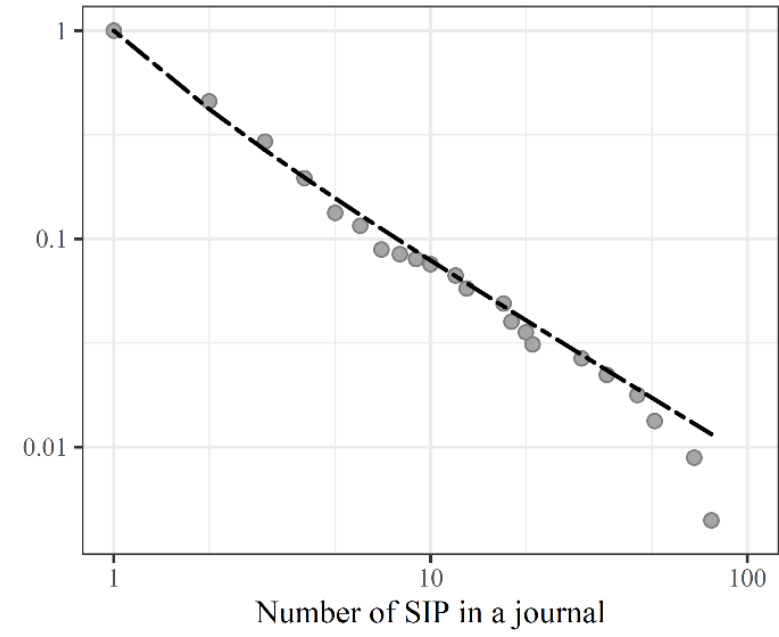

As mentioned, the exponents of the power law distributions are quite similar, but there is a larger difference than in the distribution of (N)SIP per score. To test if the differences between the two distributions are significant and to better understand the difference, we will add another measurement and visualization of the distribution. The Gini coefficient is widely used in the field of economics to describe income inequality. It measures the inequality of a frequency distribution and thus can be applied to compare the uneven distributions between journals with NSIP and SIP. A perfect equality is expressed with a Gini coefficient of zero, inequality with a coefficient of 1 . The coefficient can be understood as measurement whether a distribution is rather heterogeneous or homogeneous.

The Gini coefficient for the selection of sources with NSIP results in 0.44 (95 \%-CI: 0.36 0.52 ) and the coefficient for SIP in a value of 0.63 (95 \%-CI: 0.55 - 0.71). This means, the sources of NSIP were more homogeneously distributed than the others. The latter have a more heterogeneous distribution, which means that the top journals amount for a higher share of SIP. The distributions can be visualized in so-called Lorenz curves which normalize the frequencies. The advantage is that several distributions can be compared to each other.

Figure 3 shows the Lorenz curves for journals with NSIP and SIP. If the distribution would be on a straight diagonal line between bottom left and top right, this would represent a perfect equality. The bigger the difference between the data and the diagonal, the more unequal is the distribution. The data for NSIP (black) is more equally distributed than the data for SIP (gray). The reason for this is probably that the dominance of a few journals is more pronounced for the other disciplines. For neuroscience, $64 \%$ of all journals have published only one NSIP each and represent $29 \%$ of all NSIP. For all other disciplines, $54 \%$ of all journals have published 
one SIP each, but only represent $14 \%$ of all SIP. In this case, many more SIP are concentrated in just a few sources. While there are some journals that are preferred by journalists when they select neuroscientific results, the selection is more diverse compared to the journalistic selection of results from other disciplines.

Figure 3. Lorenz curves of journals with NSIP and SIP

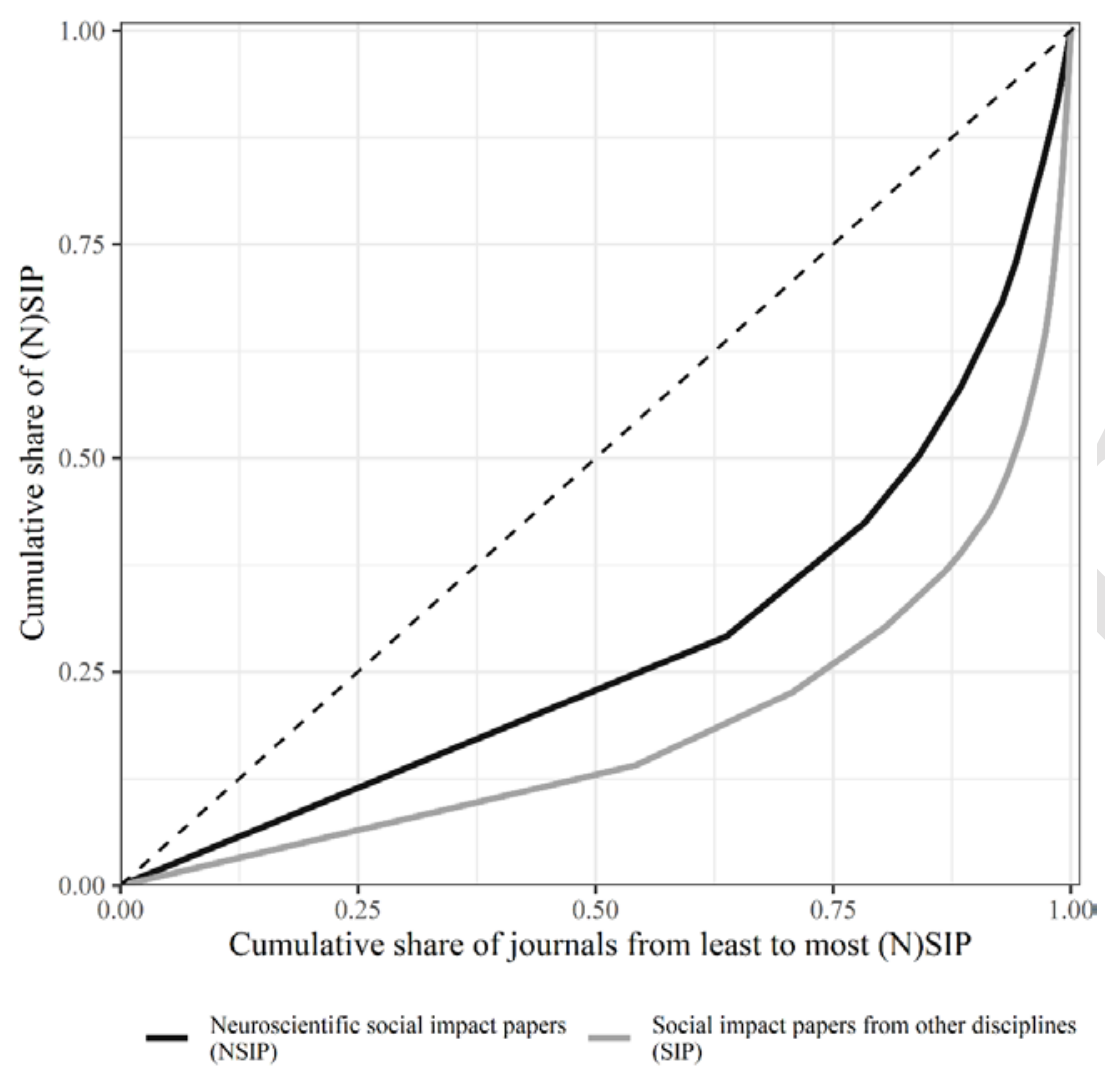

\section{Discussion}

396 This paper aimed to uncover structures on a macro-level which derive from the actions and decisions of journalists on a micro-level. The aggregation of science journalists' selections is defined as social structure which becomes visible in the distribution of the selection of research results and scientific journals. Based on the theoretical assumptions and findings of Lehmkuhl and Promies (2020), we tested the hypotheses that the frequency distribution of journalistic references to single results and scientific journals in the coverage of neuroscientific research can be described by a power law distribution. Additionally, we compared the coverage of neuroscience with other scientific fields to explore the potential of the exponent of such power laws for the analysis of differences between journalistic fields. The logic of situation and selection of science journalism lead to a heavy-tailed skewed distribution, which can be described as a transformation rule for the logic of aggregation. The 
individual selection decisions of journalists on the micro-level become visible in an aggregation

408 of all actions on a macro-level. For both the selection of single scientific results and the selection of scientific journal, we found a power law distribution, confirming our assumptions. We have thus further confirmed the results of Lehmkuhl and Promies (2020) who discussed that power

411 law distributions will probably always occur if individuals have to choose from an almost 412 infinite amount of options.

413 With regard to single scientific studies, there are no differences between neuroscientific 414 research results and other disciplines. Each were selected equally by science journalism. 415 Although the number of SIP and NSIP differs depending whether it is neuroscience $(n=151)$ or 416 not $(n=868)$, the exponent of the power law fit does not change and seems to reveal a quite 417 stable structure. Lehmkuhl and Promies (2020) came to the same conclusion on the 418 dissemination of single study findings independently from time. With regard to the selection of 419 scientific journals as sources for media coverage, we found differences between neuroscience and other research fields. The exponent for the distribution of NSIP on journals is higher than for the distribution of SIP on journals. The reason for this is that in the coverage of neuroscience the dominance of a few sources is less pronounced than in general. Journals from which only a few studies were selected by journalism represent a higher share of all NSIP. This is also reflected in a lower Gini coefficient.

This finding requires an explanation. It must be made plausible and concrete, which changes in the situation will influence concrete selection decisions of journalists on the micro level, which empirically become visible on the macro level as a structural difference in the choice of journals. We propose to interpret this structural difference as the result of a greater popularity of neuroscience compared to other fields of science. Our finding suggests, in a generalized way, that as the popularity of a discipline increases, the strong orientation of journalism towards preselection by the renowned major journals moderately weakens. The structural difference in source selection can thus plausibly be interpreted as an effect of journalism's adaptation to

433 changing audience preferences, which is structurally expressed in a greater diversity of source 434 selection.

435 Even though this conclusion appears to be plausible, the present study cannot depict the 436 decisions that actually take place on the individual level of science journalists. In any case, the 437 situation and conditions of the scientific and journalistic system must be taken into account. As 438 a premise, the selection of sources and single research findings is based on a flood of scientific 439 information. This situation influences the interdependence between science and journalism. The 
440 latter has to develop structures and criteria to manage this information overload, leading to the 441 structures we observed. If there are changes within the social structure, it will probably only 442 affect the exponent of the power law distribution and not the kind of distribution itself. Thus, 443 the comparison of the values of the exponents allow it to analyze social change. We have shown 444 that the comparison of Gini coefficients and the visualization with Lorenz curves are an 445 additional measure to find differences in such social structures.

446 Since we only conducted a first, exploratory analysis of the potential of the exponent as an 447 indicator for social change, we suggest further studies to detect differences between the 448 exponents of power law fits as well as gini coefficients as measurement of the homogeneous or 449 heterogeneous distribution of journalistic selection.

450 This study has to deal with some limitations. One affects the MSM score which we have used 451 as indicator for media coverage. It is possible, that intermedia effects might have occurred. In 452 this case and following the assumption that science journalists closely observe the media 453 coverage of other media titles, the MSM score cannot show if science journalists have selected 454 the research paper from the origin source or from other media coverage. Even more, the media 455 titles which are part of the MSM score are unsystematically chosen by the provider Altmetric. 456 Although the MSM score $\geq 100$ definitely refers to media coverage, it is not possible to assess 457 the quality of media coverage. We suggest future studies to examine the frequency distributions 458 with other indicators for media attention. 


\section{Acknowledgments}

461 We would like to thank Lars Koppers (KIT), Volker Stollorz (Science Media Center), and 462 Melanie Leidecker-Sandmann (KIT) for their comments, Estelle Dumas-Mallet and François 463 Gonon (Université de Bordeaux) for the classification of the studies, Yannick Milhan for 464 helping us extracting the data, Altmetrics for providing us the access to data, and our student 465 project group for their help. This research was supported by the German Research Foundation 466 DFG. 


\section{References}

468

469

470

471

472

473

474

475

476

477

478

479

480

481

482

483

484

485

486

487

488

489

490

491

492

493

494

495

496

Abi-Rached, J. M. (2008). The implications of the new brain sciences. The 'Decade of the Brain' is over but its effects are now becoming visible as neuropolitics and neuroethics, and in the emergence of neuroeconomies. Embo Reports, 9(12), 1158-1162. https://doi.org/10.1038/embor.2008.211

Adie, E., \& Roe, W. (2013). Altmetric: enriching scholarly content with article-level discussion and metrics. Learned Publishing, 26(1), 11-17. https://doi.org/10.1087/20130103

Allgaier, J., Dunwoody, S., Brossard, D., Lo, Y.-Y., \& Peters, H. P. (2013a). Journalism and social media as means of observing the contexts of science. BioScience, 63(4), 284-287. https://doi.org/10.1525/bio.2013.63.4.8

Allgaier, J., Dunwoody, S., Brossard, D., Lo, Y.-Y., \& Peters, H. P. (2013b). Medialized science? Neuroscientists' reflections on their role as journalistic sources. Journalism Practice, 7(4), 413-429. https://doi.org/10.1080/17512786.2013.802477

Amend, E., \& Secko, D. M. (2012). In the face of critique: A metasynthesis of the experiences of journalists covering health and science. Science Communication, 34(2), 241-282. https://doi.org/10.1177/1075547011409952

Anderson, C. (2009). The long tail: Nischenprodukte statt Massenmarkt - das Geschäft der Zukunft. Deutscher Taschenbuch-Verlag (dtv).

Badenschier, F., \& Wormer, H. (2012). Issue Selection in Science Journalism: Towards a Special Theory of News Values for Science News? In S. Rödder, M. Franzen, \& P. Weingart (Eds.), Sociology of the Sciences Yearbook: Vol. 28. The sciences' media connection: Public communication and its repercussions (pp. 59-85). Springer.

Bartlett, C. (2002). What is newsworthy? Longitudinal study of the reporting of medical research in two British newspapers. BMJ, 325(7355), 81-84. https://doi.org/10.1136/bmj.325.7355.81

Beall, J. (2013). Predatory publishing is just one of the consequences of gold open access. Learned Publishing, 26(2), 79-83. https://doi.org/10.1087/20130203

Beck, D. M. (2010). The appeal of the brain in the popular press. Perspectives on Psychological Science, 5(6), 762-766. https://doi.org/10.1177/1745691610388779

Blöbaum, B., Görke, A., \& Wied, K. (Feb. 2004). Quellen der Wissenschaftsberichterstattung. 
497

498

499

500

501

502

503

504

505

506

507

508

509

510

511

512

513

514

515

516

517

518

519

520

521

522

523

524

525

526

527

Bornmann, L., \& Mutz, R. (2015). Growth rates of modern science: A bibliometric analysis based on the number of publications and cited references. Journal of the Association for Information Science and Technology, 66(11), 2215-2222. https://doi.org/10.1002/asi.23329

Clauset, A., Shalizi, C. R., \& Newman, M. E. J. (2009). Power-law distributions in empirical data. SIAM Review, 51(4), 661-703. https://doi.org/10.1137/070710111

Coleman, J. S. (1991). Handlungen und Handlungssysteme. Grundlagen der Sozialtheorie: Vol. 1. Oldenbourg.

Cortiñas-Rovira, S., Alonso-Marcos, F., Pont-Sorribes, C., \& Escribà-Sales, E. (2015). Science journalists' perceptions and attitudes to pseudoscience in Spain. Public Understanding of Science, 24(4), 450-465. https://doi.org/10.1177/0963662514558991

Demir, S. B. (2018). Predatory journals: Who publishes in them and why? Journal of Informetrics, 12(4), 1296-1311. https://doi.org/10.1016/j.joi.2018.10.008

Dimbath, O. (2012). Einführung in die Soziologie. Fink.

Dogruel, L., \& Beck, K. (2017). Social Media als Alternative der Wissenschaftskommunikation? Eine medienökonomische Analyse. In P. Weingart, H. Wormer, A. Wenninger, \& R. F. Hüttl (Eds.), Perspektiven der Wissenschaftskommunikation im digitalen Zeitalter (pp. 123-187). Velbrück Wissenschaft.

Domingo, D., Quandt, T., Heinonen, A., Paulussen, S., Singer, J. B., \& Vujnovic, M. (2008). Participatory journalism practices in the media and beyond: an international comparative study of initiatives in online newspapers. Journalism Practice, 2(3), 326-342. https://doi.org/10.1080/17512780802281065

Donsbach, W. (2004). Psychology of news decisions: Factors behind journalists' professional behavior. Journalism, 5(2), 131-157. https://doi.org/10.1177/146488490452002

Eilders, C. (2006). News factors and news decisions. Theoretical and methodological advances in Germany. Communications, 31(1), 5-24. https://doi.org/10.1515/COMMUN.2006.002

Elsevier (Ed.). (August 2017). Scopus: Content Coverage Guide. https://www.elsevier.com/_data/assets/pdf_file/0007/69451/0597-Scopus-ContentCoverage-Guide-US-LETTER-v4-HI-singles-no-ticks.pdf

Esser. (1999). Soziologie: Allgemeine Grundlagen. Campus-Verlag.

Franzen, M. (2011). Breaking News: Wissenschaftliche Zeitschriften im Kampf um Aufmerksamkeit. Nomos. https://doi.org/10.5771/9783845231501 
Frazzetto, G., \& Anker, S. (2009). Neuroculture. Nature Reviews Neuroscience, 10(11), 815821. https://doi.org/10.1038/nrn2736

Gillespie, C. S. (2015). Fitting heavy tailed distributions: The poweRlaw package. Journal of Statistical Software, 64(2). https://doi.org/10.18637/jss.v064.i02

Granado, A. (2011). Slaves to journals, serfs to the web: The use of the internet in newsgathering among European science journalists. Journalism, 12(7), 794-813. https://doi.org/10.1177/1464884911412702

Hanitzsch, T [T.] (2009). Zur Wahrnehmung von Einflüssen im Journalismus. Komparative Befunde aus 17 Ländern. M\&K Medien \& Kommunikationswissenschaft, 57(2), 153-173. https://doi.org/10.5771/1615-634x-2009-2-153

Hansen, A. (1994). Journalistic practices and science reporting in the British press. Public Understanding of Science, 3(2), 111-134. https://doi.org/10.1088/0963-6625/3/2/001

Illes, J., Moser, M. A., McCormick, J. B., Racine, E., Blakeslee, S., Caplan, A., Hayden, E. C., Ingram, J., Lohwater, T., McKnight, P., Nicholson, C., Phillips, A., Sauvé, K. D., Snell, E., \& Weiss, S. (2010). Neurotalk: Improving the communication of neuroscience research. Nature Reviews Neuroscience, 11(1), 61-69. https://doi.org/10.1038/nrn2773

Johnson, R., Watkinson, A., \& Mabe, M. (Oct. 2018). The STM Report: An overview of scientific and scholarly publishing. International Association of Scientific, Technical and Medical Publishers (STM). https://www.stmassoc.org/2018_10_04_STM_Report_2018.pdf

Jong, I. M. de, Kupper, F., Arentshorst, M., \& Broerse, J. (2016). Responsible Reporting: Neuroimaging News in the Age of Responsible Research and Innovation. Science and Engineering Ethics, 22(4), 1107-1130. https://doi.org/10.1007/s11948-015-9684-7

Kiefer, M. (2005). Medienökonomik: Einführung in eine ökonomische Theorie der Medien. Oldenbourg.

Kiernan, V. (2016). Source diversity among journals cited in Science Times. Public Understanding of Science, 25(2), 198-206. https://doi.org/10.1177/0963662514542908

Koh, E. J., Dunwoody, S., Brossard, D., \& Allgaier, J. (2016). Mapping Neuroscientists’ Perceptions of the Nature and Effects of Public Visibility. Science Communication, 38(2), 170-196. https://doi.org/10.1177/1075547016635180 
Laakso, M., Welling, P., Bukvova, H., Nyman, L., Björk, B.-C., \& Hedlund, T. (2011). The development of open access journal publishing from 1993 to 2009. Plos One, 6(6), e20961. https://doi.org/10.1371/journal.pone.0020961

Lehmkuhl, M. (2019). Komplexität der Wissenschaft als Herausforderung für den Wissenschaftsjournalismus. In B. Dernbach, A. Godulla, \& A. Sehl (Eds.), Komplexität im Journalismus (203-212). Springer VS.

Lehmkuhl, M., \& Peters, H. P. (2016). Constructing (un-)certainty: An exploration of journalistic decision-making in the reporting of neuroscience. Public Understanding of Science, 25(8), 909-926. https://doi.org/10.1177/0963662516646047

Lehmkuhl, M., \& Promies, N. (2020). Frequency distribution of journalistic attention for scientific studies and scientific sources: An input-output analysis. Plos One, 15(11), e0241376. https://doi.org/10.1371/journal.pone.0241376

LexisNexis. (2020, March 27). Professionelle Online-Recherche-Tools. https://www.lexisnexis.de/

Manca, A., Moher, D., Cugusi, L., Dvir, Z., \& Deriu, F. (2018). How predatory journals leak into PubMed. CMAJ : Canadian Medical Association Journal = Journal De L'association Medicale Canadienne, 190(35), E1042-E1045. https://doi.org/10.1503/cmaj.180154

Marcinkowski, F., Kohring, M., Fürst, S., \& Friedrichsmeier, A. (2014). Organizational influence on scientists' efforts to go public: an empirical investigation. Science Communication, 36(1), 56-80. https://doi.org/10.1177/1075547013494022

Mellor, F. (2015). Non-news values in science journalism. In B. Rappert \& B. Balmer (Eds.), Global Issues Series. Absence in Science, Security and Policy: From Research Agendas to Global Strategy (Vol. 106, pp. 93-113). Palgrave Macmillan. https://doi.org/10.1057/9781137493736_5

Moriarty, C. M., Jensen, J. D., \& Stryker, J. E. (2010). Frequently cited sources in cancer news coverage: a content analysis examining the relationship between cancer news content and source citation. Cancer Causes \& Control, 21(1), 41-49. https://doi.org/10.1007/s10552009-9432-x

Newman, M. (2005). Power laws, Pareto distributions and Zipf's law. Contemporary Physics, 46(5), 323-351. https://doi.org/10.1080/00107510500052444

O'Connell, G., ～Wilde, J. de, Haley, J., $\quad$ Shuler, K., $\quad$ Schafer, B., $\quad$ Sandercock, P., ～\& Wardlaw, J. M. (2011). The brain, the science and the media. The legal, corporate, social 
and security implications of neuroimaging and the impact of media coverage. Embo Reports, 12(7), 630-636. https://doi.org/10.1038/embor.2011.115

O'Connor, C., \& Joffe, H. (2013a). How has neuroscience affected lay understandings of personhood? A review of the evidence. Public Understanding of Science. Advance online publication. https://doi.org/10.1177/0963662513476812

O'Connor, C., \& Joffe, H. (2013b). Media representations of early human development: Protecting, feeding and loving the developing brain. Social Science \& Medicine (1982), 97, 297-306. https://doi.org/10.1016/j.socscimed.2012.09.048

O'Connor, C., \& Joffe, H. (2014). Gender on the brain: A case study of science communication in the new media environment. Plos One, 9(10), e110830. https://doi.org/10.1371/journal.pone.0110830

O'Connor, C., Rees, G., \& Joffe, H. (2012). Neuroscience in the public sphere. Neuron, 74(2), 220-226. https://doi.org/10.1016/j.neuron.2012.04.004

O'Neill, D., \& Harcup, T. (2008). News values and selectivity. In K. Wahl-Jorgensen \& T. Hanitzsch (Eds.), International Communication Association handbook series. The handbook of journalism studies (pp. 161-174). Routledge.

Pahl, C. (1997). Die Bedeutung von Wissenschaftsjournalen für die Themenauswahl in den Wissenschaftsressorts deutscher Zeitungen am Beispiel medizinischer Themen: Forschungsbericht. Berlin. FU Berlin. http://www.polsoz.fuberlin.de/kommwiss/arbeitstellen/wissenskommunikation/media/pahl_fobe1.pdf

Peters, H. P., Allgaier, J., Dunwoody, S., Lo, Y.-Y., Brossard, D., \& Jung, A. (2013). Medialisierung der Neurowissenschaften.: Bedeutung journalistischer Medien für die Wissenschafts-Governance. In E. Grande, D. Jansen, O. Jarren, A. Rip, U. Schimank, \& P. Weingart (Eds.), Neue Governance der Wissenschaft: Reorganisation - externe Anforderungen - Medialisierung (pp. 311-335). transcript Verlag.

Pickersgill, M. (2013). The social life of the brain: Neuroscience in society. Current Sociology, 61(3), 322-340. https://doi.org/10.1177/0011392113476464

R Core Team. (2019). R: A Language and Environment for Statistical Computing [Computer software]. Vienna, Austria. https://www.R-project.org/

Racine, E., Bar-Ilan, O., \& Illes, J. (2006). Brain Imaging: A Decade of Coverage in the Print $\begin{array}{llll}\text { Media. Science } & \text { Communication, }\end{array}$ https://doi.org/10.1177/1075547006291990 
622 Racine, E., Nguyen, V., Saigle, V., \& Dubljevic, V. (2017). Media Portrayal of a Landmark

623 Neuroscience Experiment on Free Will. Science and Engineering Ethics, 23(4), 989-1007.

624 https://doi.org/10.1007/s11948-016-9845-3

625 Racine, E., Waldman, S., Rosenberg, J., \& Illes, J. (2010). Contemporary neuroscience in the 626 media. Social Science \& $\quad$ Medicine, 71(4), 725-733. https://doi.org/10.1016/j.socscimed.2010.05.017

628 Reinemann, C., \& Huismann, J. (2007). Beziehen sich Medien immer mehr auf Medien? Publizistik, 52(4), 465-484. https://doi.org/10.1007/s11616-007-0243-3

630

Rodriguez, P. (2006). Talking brains: a cognitive semantic analysis of an emerging folk neuropsychology. Public Understanding of Science, 15(3), 301-330. https://doi.org/10.1177/0963662506063923

Rosen, C., Guenther, L., \& Froehlich, K. (2016). The Question of Newsworthiness. Science Communication, 38(3), 328-355. https://doi.org/10.1177/1075547016645585

635

636

637

638

639

640

641

642

643

644

645

646

647

648

649

650

651

652

653

Schäfer, M. S. (2011). Sources, Characteristics and Effects of Mass Media Communication on Science: A Review of the Literature, Current Trends and Areas for Future Research. Sociology Compass, 5(6), 399-412. https://doi.org/10.1111/j.1751-9020.2011.00373.x

Scheufele, D. A. (2013). Communicating science in social settings. Proceedings of the National Academy of Sciences of the United States of America, 110 Suppl 3, 14040-14047. https://doi.org/10.1073/pnas.1213275110

Schimank, U. (2005). Die Entscheidungsgesellschaft: Komplexität und Rationalität der Moderne. Hagener Studientexte zur Soziologie. VS Verlag für Sozialwissenschaften. http://dx.doi.org/10.1007/978-3-322-80606-2 https://doi.org/10.1007/978-3-322-80606-2

Schneider, W. L. (2005). Garfinkel - RC - Habermas - Luhmann. Grundlagen der soziologischen Theorie: Vol. 2. VS Verl. für Sozialwiss.

Semir, V. de (1998). Press Releases of Science Journal Articles and Subsequent Newspaper Stories on the Same Topic. JAMA, 280(3), 294. https://doi.org/10.1001/jama.280.3.294

Smyrnaios, N., Marty, E., \& Rebillard, F. (2010). Does the Long Tail apply to online news? A quantitative study of French-speaking news websites. New Media \& Society, 12(8), 12441261. https://doi.org/10.1177/1461444809360699

Stryker, J. E. (2002). Reporting Medical Information: Effects of Press Releases and Newsworthiness on Medical Journal Articles' Visibility in the News Media. Preventive Medicine, 35(5), 519-530. https://doi.org/10.1006/pmed.2002.1102 
654 Suleski, J., \& Ibaraki, M. (2010). Scientists are talking, but mostly to each other: A quantitative 655 analysis of research represented in mass media. Public Understanding of Science, 19(1), 656 115-125. https://doi.org/10.1177/0963662508096776

657 


\section{Supplement}

Table S1 Research branch and percentages of SIP

\begin{tabular}{|l|l|l|}
\hline research branch & Number of SIP & \% \\
\hline medicine & 378 & 37,10 \\
\hline neurology, neuroscience & 151 & 14,82 \\
\hline biology & 91 & 8,93 \\
\hline psychiatry & 66 & 6,48 \\
\hline astronomy & 63 & 6,18 \\
\hline ecology geography and related sciences & 53 & 5,20 \\
\hline anthropology and paleontology & 45 & 4,42 \\
\hline climatology & 44 & 4,32 \\
\hline psychology & 42 & 4,12 \\
\hline others & 86 & 8,44 \\
\hline
\end{tabular}

$\mathrm{N}=1019$ SIP

661

Table S2. Parameters of Power Law fits and results of goodness-of-fit tests

\begin{tabular}{|l|l|l|}
\hline Data & \multicolumn{1}{|c|}{$\boldsymbol{\alpha}(\mathrm{SE})$} & \multicolumn{1}{|c|}{ p-value } \\
\hline NSIP per journal & $2.149(0.385)$ & 0.759 \\
\hline SIP per journal & $1.921(0.133)$ & 0.109 \\
\hline NSIP per MSM score & $3.967(0.390)$ & 0.734 \\
\hline SIP per MSM score & $4.027(0.762)$ & 0.350 \\
\hline
\end{tabular}

*Significant p-values will reject the power law hypothesis (goodness-of-fit test).

\section{Detailed description of analysis}

666 We followed the methodology presented by Clauset et al. (2009) to estimate the parameters and 667 plausibility of a power law distribution in our data. The first step in this approach is usually to 668 estimate the parameter Xmin, which yields the lower bound of the power law behaviour in the 669 data. To find Xmin, a Kolmogorov-Smirnov (KS) approach is used that calculates the maximum 670 distance between the CCDFs of the data and the fitted model for different values of $x_{\text {min. }}$ The 
671 estimate of $\mathrm{Xmin}$ is the value that minimizes the distance. Because we assumed that the power

672 law behaviour would be present in all of our data, we did not use this approach and fixed $\mathrm{Xmin}_{\min }$

673 to be 1 for the distribution of journals and 100 for the distribution of MSM scores. Once we

674 know from which value we can fit a power law distribution to our data, we can estimate the

675 exponent of the power law distribution $\alpha$ with a maximum likelihood estimator (MLE). To get

676 a measure for the uncertainty of these estimates, we use a bootstrapping approach in which we

677 estimate $\mathrm{Xmin}$ and $\alpha$ for a number of synthetic datasets generated from the original data and take

678 the standard deviation over all datasets. We used 10,000 simulations for this step.

679 After these steps, we merely have more reliable estimates of the parameters of a possible power 680 law fit to our data, but we do not yet know whether this fit is plausible. To get a visual 681 impression of the plausibility of the power law fit, we calculated the complementary cumulative 682 distribution function (CCDF) of our data. For a less subjective estimate of the plausibility of 683 the power law fit, Clauset et al. propose two techniques. We applied the first, which is a 684 goodness-of-fit test, again using the KS statistic. It tests the hypothesis that the observed data 685 are drawn from a power-law distribution [86]. We used 10,000 simulations here, as well. In our 686 analysis, we used the implementation of these methods in the R package poweRlaw. We used 687 the versions of the methods adjusted for calculations with discrete data. 